\title{
Internacionalizaçao curricular no sul-global: uma perspectiva critica a partir dos conceitos de reduçao sociológica e de epistemologias do sul
}

\author{
DOI: http://dx.doi.org/10.25087/resur3a1
}

\author{
Fernanda Geremias Leal ${ }^{1}$ \\ Mário César Barreto Moraes ${ }^{2}$
}

Recibido, 4 de marzo de 2017

Aprobado, 18 de mayo de 2017

\section{Resumo}

A internacionalização do currículo tem se destacado como componente essencial das agendas de internacionalização da educação superior, levando organizações governamentais e intergovernamentais a realçarem a necessidade de reformas curriculares condizentes com as demandas globais, que incorporem os conceitos de cidadania global e de competência intercultural como objetivos centrais desse processo. Diante do pressuposto de que a inserção dos países periféricos e semiperiféricos no contexto da educação superior internacional tende a assumir caráter predominantemente passivo, levando a um imaginário de reformas curriculares despreparadas para envolver os estudantes criticamente na complexidade do mundo globalizado, o objetivo deste trabalho é promover uma reflexão sobre a internacionalização do currículo no contexto do Sul-Global. Trata-se de um ensaio teórico, que, por meio dos conceitos de redução sociológica, de Alberto Guerreiro Ramos, e de epistemologias do Sul, de Boaventura de Sousa Santos, busca enfatizar as especificidades e as raízes epistêmicas dos contextos em que esses processos ocorrem. A interação entre a literatura sobre globalização, internacionalização da educação superior e internacionalização do currículo com os referidos conceitos permitiu apontar para a necessidade de que as políticas de internacionalização dos processos de ensino e aprendizagem do Sul-Global tenham como referência um procedimento crítico-assimilativo da experiência estrangeira, pautado em conhecimento prudente, válido, que enfatize a descolonização do saber e seja funcional e significativo à sua realidade, visto que o sentido de um objeto jamais se desliga de determinado contexto.

\footnotetext{
${ }^{1}$ Doutoranda em Administração na Universidade do Estado de Santa Catarina (UDESC), Florianópolis, Brasil. fernanda.leal@ufsc.br

${ }^{2}$ Doutor em Engenharia de Produção. Professor do Programa de Pós-graduação em Administração da Universidade do Estado de Santa Catarina (UDESC), Florianópolis, Brasil mcbmstrategos@gmail.com
} 
Palavras-chave: Internacionalização. Educação superior. Redução sociológica. Epistemologias do Sul.

\section{Resumen}

La internacionalización del currículo se ha destacado como componente esencial en las discusiones sobre internacionalización de la educación superior, motivando a que organizaciones gubernamentales e intergubernamentales realcen la necesidad de responder a las demandas globales, incorporando los conceptos de ciudadanía global y de interculturalidad como objetivos centrales. Ante el supuesto de que la inserción de los países periféricos y semi-periféricos en el contexto de la educación superior internacional tiende a asumir un carácter predominantemente pasivo, conduciendo a un imaginario de reformas curriculares que no involucran a los estudiantes de manera crítica y menos aún en la complejidad del mundo globalizado, el objetivo de este trabajo es promover una reflexión sobre la internacionalización del currículo en el contexto del Sur-Global. Se trata de un ensayo teórico que a través de los conceptos de reducción sociológica, de Alberto Guerrero Ramos, y de epistemologías del Sur, de Boaventura de Sousa Santos, busca dar énfasis a las especificidades y a las raíces epistémicas de los contextos en que esos procesos ocurren. La interacción entre la literatura sobre globalización, internacionalización de la educación superior e internacionalización del currículo permitió apuntar a la necesidad de que las políticas de internacionalización de los procesos de enseñanza y aprendizaje del Sur-Global traigan como referencia un procedimiento crítico-asimilatorio de la experiencia extranjera, en bases a un conocimiento prudente, adonde la descolonización del saber sea una meta constante. Vale decir: un conocimiento funcional que permite valorar y dar significación a la realidad, una vez que el sentido de un objeto jamás puede estar desligado de su proprio y determinado contexto.

Palabras-clave: Internacionalización. Educación universitaria. Reducción sociológica. Epistemologías del Sur.

\section{Abstract}

The internationalization of the curriculum has been highlighted as an essential component of the internationalization of higher education agenda, leading governmental and intergovernmental organizations to emphasize the need for curricular reforms that 
are consistent with the global demands, incorporating the concepts of global citizenship and intercultural competence as the central objectives of this process. Given the assumption that the participation of peripheral and semiperipheral countries in the context of international higher education tends to assume a predominantly passive character, leading to an imaginary of unprepared curricular reforms to critically involve students in the complexity of the globalized world, the objective of this work is to promote a reflection on the internationalization of the curriculum in the context of the South-Global. This is a theoretical essay that, through the concepts of sociological reduction, by Alberto Guerreiro Ramos, and epistemologies of the South, by Boaventura de Sousa Santos, seeks to emphasize the specificities and the epistemic roots of the contexts in which these processes occur. The interaction between the literature on globalization, internationalization of higher education and internationalization of the curriculum with these concepts allowed us to point out the need for internationalization policies of the teaching and learning processes in the Global-South to have a critical-assimilative procedure of the foreign experience as reference, based on prudent, valid knowledge, that emphasizes the decolonization of knowledge and is functional and meaningful to its reality, since the meaning of an object is never disconnected from a given context.

Keywords: Internationalization. Higher Education. Sociological reduction. Epistemologies of the South.

\section{Introduçao}

A internacionalização do currículo - comumente definida como o processo de integração das dimensões internacional, intercultural e global aos processos de ensino e aprendizagem da educação superior - tem se destacado como componente essencial das agendas de internacionalização (Knight, 2012; Leask, Beelen \& Kaunda, 2013; Leask, 2015; Baldassar \& Mckenzie, 2016).

A percepção desse conceito passou a constituir-se como uma espécie de clichê não somente para universidades, mas também para organizações governamentais e intergovernamentais envolvidas no contexto da educação superior, as quais ressaltam a necessidade de reformas curriculares mais condizentes com as demandas globais (Rizvi, 2007). Entretanto, tais instituições raramente conferem centralidade aos meios de 
operacionalização desse conceito. De modo análogo, não atribuem significados claros aos termos "cidadania global" e "competência intercultural", unanimemente apontados como os resultados mais esperados desse processo (Leask, Beelen \& Kaunda, 2013).

Além disso, alguns dos interesses emergentes nesse domínio parecem se contextualizar antes segundo uma perspectiva exclusivamente amparada no instrumentalismo econômico e voltada à competitividade do mercado, do que associados a uma perspectiva de real aprimoramento da qualidade, da pertinência e da relevância do ensino, elementos constantemente enfatizados como centrais aos processos de internacionalização (Rizvi, 2007; Lima \& Contel, 2011).

$\mathrm{Na}$ expectativa de integrar-se ao contexto da educação superior internacional, instituições universitárias dos países do $\mathrm{Sul}^{3}$ têm buscado internacionalizar seus currículos. Contudo, tais tentativas dificilmente consideram os fatores situacionais e o contexto histórico-social em que essas elas se situam, em parte devido à colonialidade que permeia as diversas esferas do poder, do saber e do ser. Como consequência, esse imaginário tem induzido a reformas curriculares limitadas em escopo e despreparadas para envolver os estudantes criticamente na complexidade do mundo globalizado (Rizvi, 2007; Lima \& Contel, 2011).

Diante do pressuposto de que a inserção dos países periféricos e semiperiféricos no contexto da educação superior internacional tem assumido caráter predominantemente passivo, em obediência a uma lógica antes reativa do que deliberativa (Unesco, 2003; Lima \& Contel, 2011), torna-se relevante a exploração de caminhos alternativos pouco esmiuçados, que tragam novas perspectivas acerca das bases nas quais uma internacionalização curricular alternativa, voltada à resolução de problemas concretos das realidades locais e à emancipação e à autonomia dos indivíduos, pode se amparar.

O objetivo deste ensaio é promover uma reflexão sobre a internacionalização do currículo nos países do Sul, a partir de dos conceitos sociológicos associados à teoria pós-colonial: redução sociológica, de Alberto Guerreiro Ramos, e epistemologias do Sul, de Boaventura de Sousa Santos. Busca-se estabelecer um diálogo que tenha como

\footnotetext{
${ }^{3}$ Compreende-se o Sul-Global ou o Sul "não como uma categoria geográfica, mas como o agrupamento que reúne os chamados 'países em desenvolvimento' (países de renda média e países de renda baixa)" (LEITE, 2012, p. 4). Para Sousa Santos e Meneses (2010, p. 19) "o Sul é aqui concebido metaforicamente como um campo de desafios epistêmicos, que procuram reparar os danos e impactos historicamente causados pelo capitalismo na sua relação colonial com o mundo".
} 
referencial uma perspectiva crítica dos processos de internacionalização e que contemple as especificidades e as raízes epistêmicas dos contextos onde os processos ocorrem.

A fim de estabelecer uma compreensão conceitual sobre os caminhos que têm orientado a educação superior, inicialmente apresentaremos os significados atribuídos aos termos internacionalização e globalização, frequentemente usados como sinônimos na literatura. Em seguida, trataremos da internacionalização curricular, considerando suas oportunidades e desafios, bem como o posicionamento e as perspectivas dos países do Sul nesse contexto. Na sequência, apresentaremos os conceitos de redução sociológica e de epistemologia do Sul como elementos contributivos para a discussão sobre internacionalização curricular. Por fim, apontaremos algumas considerações e as referências bibliográficas.

Metodologicamente, trata-se de um ensaio de natureza teórica. Portanto, não envolve a exploração de recursos metodológicos empíricos. O texto foi desenvolvido a partir de referenciais bibliográficos que trataram dos temas globalização, internacionalização da educação superior e internacionalização do currículo, em interação com os conceitos de redução sociológica e de epistemologias do Sul.

\section{Globalizaçao e internacionalizaçao da educação superior}

Um dos discursos mais utilizados nas referências à década de 1990 é o da globalização (Wallerstein, 2004). Em termos gerais, esse conceito tem sido trabalhado segundo uma perspectiva neutra; como processo de intensificação das interações transfronteiriças, que aproxima nações e influencia seus processos sociais, econômicos, políticos e culturais. Nessa perspectiva, o contexto histórico, as tradições e as prioridades dos países definem a maneira como a globalização os afeta (Knight \& De Wit, 1997; Knight, 2004, 2008, 2012).

Sousa Santos (2011, p. 27) apresenta uma caracterização mais crítica para o conceito ao constatar que "a globalização, longe de ser consensual, é um vasto e intenso campo de conflitos entre grupos sociais, Estados e interesses hegemônicos, por um lado, e grupos sociais, Estados e interesses subalternos, por outro". Em sua perspectiva, o campo hegemônico, constituído pelos Estados centrais do sistema mundial, impõe determinadas características aos demais, relativas principalmente às políticas mundiais 
de desenvolvimento e ao papel do Estado na Economia. Tais características se legitimam como as únicas possíveis ou adequadas. Segundo Andion (2012, p. 10), essa prescrição, que se baseia em uma agenda neoliberal e emerge como única possibilidade, "nega a capacidade de reação dos Estados nacionais e os coloca como mero objetos passivos das forças externas, as quais não podem controlar e devem então apenas se submeter".

Para Sousa Santos (2011), os países periféricos e semiperiféricos são aqueles para os quais as características dominantes do que ele intitula de globalização neoliberal são mais fortemente impostas, sobretudo por meio dos programas de ajustamento estrutural, criados pelas instituições financeiras multilaterais como condição para a renegociação de suas dívidas externas. Em suas palavras (Sousa Santos, 2011, p. 53),

"se para alguns ela [a globalização] continua a ser considerada como o grande triunfo da racionalidade, da inovação e da liberdade, capaz de produzir progresso infinito e abundância ilimitada, para outros ela é anátema, já que no seu bojo transporta a miséria, a marginalização e a exclusão da grande maioria da população mundial, enquanto a retórica do progresso e da abundância se torna em realidade apenas para um clube cada vez mais pequeno de privilegiados".

Sob esse olhar, os tempos de globalização exprimem conflitos entre o global e o local e geografias da desigualdade produzidas pelo sistema-mundo, que transformam o território em objeto a ser analisado sob o ponto de vista histórico (Santos, Souza \& Silveira, 2002; Wallerstein, 2004; Santos, 2013). Para Santos (2013), devemos considerar a existência de pelo menos três mundos em um só: globalização como fábula - o mundo tal como nos fazem vê-lo; globalização como perversidade - o mundo tal como ele é; e uma outra globalização - o mundo como ele pode ser. Enquanto como fábula, da globalização se depreende uma perspectiva utópica; como perversidade, ela é preliminarmente compreendida segundo um posicionamento marxista (Marx \& Engels, 2003), ensejando à última a dimensão das possibilidades (Santos, 2013).

Nesse aspecto, a Organização das Nações Unidas para a Educação, a Ciência e a Cultura (UNESCO) (2003) reconhece que ao mesmo tempo em que a globalização proporciona oportunidades significativas para o aprimoramento da humanidade, no estágio recente em que se encontra ela implica no aumento da competitividade e da 
tecnologia em níveis para os quais muitas nações não estão preparadas. Assim, seus benefícios são distribuídos desigualmente.

Assim como a globalização, a internacionalização também se caracteriza como um processo, embora distinto. Uma breve retrospectiva histórica revela que aquilo que se entende por trocas científicas e culturais no âmbito da educação superior esteve presente nas universidades desde sua origem (Miura, 2009; Altbach \& De Wit, 2015), com a atuação de professores provenientes de diferentes partes do mundo, recrutados para dar início às primeiras atividades de ensino e pesquisa. Contudo, foi somente no fim da década de 1970 que o termo emergiu nesse contexto e a partir de 1980 que começou a adquirir popularidade (Knight, 2004; 2008; Morosini, 2006; Lima \& Maranhão, 2011; Laus, 2012).

Nos anos 1990, a internacionalização da educação superior fortificou-se mundialmente e, desde então, sua influência em torno das estruturas universitárias e dos planejamentos estratégicos institucionais e governamentais tem sido crescente. A inclusão da Cooperação Internacional ao lado dos conteúdos "Relevância", "Melhoria da Qualidade" e "Administração e Financiamento" na Conferência Mundial sobre Educação Superior, realizada em 1998 pela UNESCO, por exemplo, demonstra que a internacionalização teve sua abrangência, sua escala e seu valor ampliados. Apesar desse destaque, não há consenso sobre o significado de internacionalização e tampouco existe um modelo padronizado para que as universidades se internacionalizem (Knight, $2004 ; 2015)$.

Com vistas a estabelecer uma definição que apresente "generalidade suficiente por ser aplicável a diferentes países, culturas e sistemas educacionais” (Knight, 2004, p. 11, tradução nossa), neste ensaio conceituamos internacionalização da educação superior como o processo de integração das dimensões internacional, intercultural e global aos propósitos, às funções primárias (ensino, pesquisa e extensão) e à entrega da educação superior nos níveis institucional e nacional (Knight, 2004). O termo tende a ser relacionado a um conjunto de atividades acadêmicas e administrativas decorrentes do estabelecimento de colaborações internacionais, desenvolvidas pelas instituições universitárias e centros de pesquisa em seus próprios campi (internationalization at home) e no exterior (internationalization abroad/crossborder internationalization) (Knight, 2012, 2015). Sob essa perspectiva, os indicadores de internacionalização mais 
recorrentes são a mobilidade acadêmica e a internacionalização do currículo, bem como os projetos de investigação transfronteiriços e as publicações conjuntas (Ewert, 2012).

Para Knight (2004), a internacionalização precisa ser compreendida nos níveis nacional e institucional. Enquanto o setor nacional influencia substancialmente a dimensão internacional das instituições universitárias, por meio de financiamentos, políticas, programas e marcos regulatórios, é no âmbito das instituições universitárias que o processo ocorre.

Os resultados do 4th Global Survey on Internationalization da International Association of Universities (IAU) ${ }^{4}$ revelam que os princípios e valores das políticas de internacionalização no nível institucional têm se orientado principalmente por rationales de natureza acadêmica (Egron-Polak; Hudson, 2014). Nas palavras de Sebástian (2004, p. 17, tradução nossa), isso significaria utilizar a internacionalização como meio para

"melhorar a qualidade, a pertinência e a relevância do ensino, da pesquisa e da extensão; articular a instituição no contexto mundial da Educação Superior; abrir novos espaços para a projeção internacional e a vinculação com redes acadêmicas internacionais; consolidar valores como a cooperação e a solidariedade na cultura institucional e ampliar as oportunidades de emprego aos egressos".

No entanto, se por um lado as rationales acadêmicas descaracterizam a internacionalização da educação superior como resposta acrítica da globalização, por outro, há que se considerar os contextos histórico-sociais, culturais, econômicos e políticos em que os processos se integram (Seeber et al., 2016), o que, na atual conjuntura, significa reconhecer as consequências das características dominantes da globalização para os diferentes sistemas educacionais (Gomes, Robertson \& Dale, 2012) e os riscos de que a Universidade seja reduzida às demandas do sistema produtivo (Lima \& Maranhão, 2011).

Nesse aspecto, Whitsed e Green (2016, p. 2, tradução nossa) argumentam que “na era da 'multiversidade' global, na qual a educação superior é largamente capturada pelo imaginário neoliberal do discurso público e político, tradições e perspectivas

\footnotetext{
${ }^{4}$ A pesquisa foi realizada com 1336 instituições universitárias de 131 países de todas as regiões do mundo. A maior parte das instituições respondentes era pública, focada em ensino e pesquisa, oferecia cursos em todos os níveis e era relativamente pequena em termos de número de matrículas (abaixo de cinco mil estudantes) (Egron-Polak; Hudson, 2014).
} 
estabelecidas sobre o papel, a função e o lugar das universidades são desafiados". Altbach e De Wit (2015, p. 9, tradução nossa) complementam que pode-se falar de uma internacionalização da educação superior globalizada, em que as formas tradicionais de cooperação e intercâmbio estão cada vez mais em conflito com as formas mais comerciais de internacionalização - como o recrutamento de estudantes, a competição por talentos e acadêmicos e a influência dos rankings universitários internacionais.

Observa-se que a influência da globalização em curso no campo da educação superior tem se manifestado principalmente na competitividade e na comercialização que se fazem presentes nesse meio. Alguns indicativos claros dessa tendência são a categorização do setor como serviço no Acordo Geral sobre Comércio e Serviços (GATS) da Organização Mundial do Comércio (OMC); a diminuição do financiamento público para a educação superior em diversos países e os consequentes processos de privatização universitária (Unesco, 2003; Sebastián, 2004; Morosini, 2006; Lima \& Contel, 2011).

Esses fatores têm sido associados a uma série de ameaças para a qualidade da educação superior e, sobretudo, para o aumento da marginalização dos países do Sul, uma vez que seus sistemas educacionais não estão bem preparados para capitalizar sobre a criação e o uso do conhecimento (Unesco, 2003). Entre tais ameaças, destacamse a ascensão de fornecedores privados de serviços educacionais e as indústrias de certificação; o "big business" do recrutamento de estudantes internacionais e a dependência de alguns países em relação às taxas de estudantes de outros países; a supervalorização dos rankings universitários e o aumento da competitividade entre pesquisadores e instituições; a hegemonia dos países do Norte no recebimento dos fluxos de mobilidade e na oferta de produtos e serviços educacionais; a evasão dos cérebros (brain drain) e a apropriação do conhecimento.

Diante desse cenário, infere-se que todo processo de internacionalização se constrói e se desenvolve a partir da situação de cada contexto e de cada sistema educacional, com suas forças e fragilidades, que determinam o potencial e a viabilidade de suas estratégias (Gacel-Ávila \& Avila, 2008). Como Lima e Contel (2011, p. 16) reconhecem, o atual quadro de internacionalização se molda em função do comportamento de cada nação. Enquanto alguns países do centro do sistema-mundo assumem papéis mais protagonistas, a maioria dos demais "segue a reboque esse 
comando ativo dos países centrais, fornecendo cérebros, recursos financeiros e comprando "produtos educacionais"".

Nesse sentido, a percepção de que "o conhecimento é universal e a sua busca e os seus progressos se baseiam na livre circulação das ideias através das fronteiras, dos campos científicos e das disciplinas acadêmicas" (Unesco, 2003, p. 99) tem implicado em desafios significativos para as nações incapazes de inserir-se ativamente no campo da educação superior internacional contemporânea.

\section{Internacionalizaçao do currículo: oportunidades e desafios}

A despeito da ênfase que as instituições universitárias têm conferido à sua dimensão internacional, a mobilidade em outro país ainda permanece reservada a uma minoria da comunidade estudantil. Esse motivo, associado ao fato de que muitas dessas instituições buscam recrutar estudantes internacionais exclusivamente pela necessidade ou pelo interesse em gerar receita, tem levado a internacionalização do currículo a apresentar-se como um componente essencial das agendas de internacionalização (Knight, 2012; Leask, Beelen \& Kaunda, 2013; Leask, 2015; Baldassar \& Mckenzie, 2016).

A internacionalização curricular está estreitamente relacionada à ideia de internacionalização em casa (internationalization at home), que, em síntese, corresponde a quaisquer atividades de natureza internacional que aconteçam na instituição de origem, à exceção da saída de um membro da comunidade universitária para realizar mobilidade. Sua centralidade está na integração das dimensões internacional, intercultural e global aos processos de ensino e aprendizagem (Leask, Beelen \& Kaunda, 2013; Leask, 2015; Baldassar \& Mckenzie, 2016).

O termo internacionalização em casa foi usado pela primeira vez em 1999 na recém-inaugurada Malmö University, da Suécia, por Bengt Nilsson, gestor de Cooperação Internacional à época (Leask, Beelen \& Kaunda, 2013; Leask, 2015; Baldassar \& Mckenzie, 2016). Ciente de que a instituição ainda não desfrutava de uma rede expressiva de cooperação para oferecer a experiência de intercâmbio no exterior aos seus estudantes, Nilsson buscou oportunizar tais experiências "em casa", com ênfase na diversidade e nos aspectos interculturais presentes naquele meio. 
Portanto, a ideia de internacionalização em casa foi desenvolvida para elevar a importância dos elementos internos da universidade, com ênfase nas dimensões internacional, intercultural, global e local que se estabelecem no ensino, na pesquisa, nas atividades extracurriculares, nas relações como grupos locais comunitários, assim como na integração da comunidade internacional às atividades e à vida no campus (Knight, 2008). Trata-se de um caminho alternativo ou complementar para internacionalizar, no sentido de aprimorar as competências da instituição de origem e, ao mesmo tempo, superar as limitações inerentes à realização da mobilidade internacional.

Neste ensaio, entendemos currículo como a função universitária de ensino e internacionalização do currículo como uma modalidade de internacionalização em casa, especificamente a integração das dimensões internacional, intercultural e global aos processos de ensino e aprendizagem. Consideramos que do mesmo modo que a internacionalização em casa, a internacionalização do currículo é altamente contextual, adquire caráter distintivo em cada circunstância em que ocorre. Desse modo, suas motivações e formas de condução variam significativamente entre países, instituições, cursos e disciplinas (Leask, Beelen \& Kaunda, 2013; Leask, 2015). O conceito foi definido pela primeira vez em 1994, pela Organização para a Cooperação e Desenvolvimento Econômico (OCDE), e, desde então, muitas definições foram propostas (Whitsed \& Green, 2016).

Apesar dessa diversidade, a literatura é unânime em relação aos resultados esperados deste processo e aponta "cidadania global" e "competência intercultural" como os principais deles. $\mathrm{O}$ primeiro tem sido associado à preparação dos estudantes para viver e trabalhar em um mundo globalizado e interconectado (Leask, Beelen \& Kaunda, 2013; Leask, 2015; Whitsed \& Green, 2016). Na visão da Unesco (2016, p. 14), "a cidadania global refere-se ao sentimento de pertencer a uma comunidade mais ampla e a uma humanidade comum. Ela enfatiza a interdependência e a interconexão política, econômica, social e cultural entre os níveis local, nacional e global”.

Segundo Deardorff e Jones (2012), a noção de cidadania global tornou-se parte do discurso sobre internacionalização ao redor do mundo. Contudo, não há consenso sobre o significado e a natureza de tal competência. Os meios para desenvolvê-la e avaliá-la também permanecem indefinidos. Como a própria Unesco (2015, p. 14) 
reconhece, "cidadania global é um conceito contestado no discurso acadêmico e existem múltiplas interpretações sobre o significado de ser um cidadão global".

O segundo resultado esperado, "competência intercultural", relativo à capacidade de comunicar-se efetivamente e de comportar-se adequadamente em situações sociais e profissionais variadas, frente a diferentes culturas, também enfrenta certa obscuridade (Leask, Beelen \& Kaunda; 2013; Leask, 2015). Algumas tensões que se estabelecem no processo de busca por um currículo internacionalizado, resultantes da questão fundamental de "como promover a universalidade (por exemplo, identidades, interesses, participação e deveres comuns e coletivos) e, simultaneamente, respeitar a singularidade (por exemplo, direitos individuais e autoaperfeiçoamento) " (Unesco, 2015, p. 18) tendem a ser desconsideradas.

Verifica-se, assim, que as pesquisas relativas a este campo têm focado antes nos resultados do que no processo de internacionalização curricular (Rizvi, 2007), de modo que raras informações são fornecidas sobre como esses resultados são operacionalmente facilitados e alcançados na prática (Baldassar \& Mckenzie, 2016).

Para Baldassar e McKenzie (2016), associada à retórica de que a internacionalização do currículo desenvolve em seus participantes uma perspectiva internacional que os transforma em "cidadãos globais", dotados de "competências interculturais", muitas vezes está a suposição de que tais resultados ocorram automaticamente, como consequência direta da mera presença de estudantes de outras nacionalidades nos cursos ou do uso de idioma estrangeiro em sala de aula. Entretanto, muitas vezes os estudantes nacionais e internacionais habitam em "mundos distintos", com poucas oportunidades concretas de engajamento, a despeito da sua proximidade física. Além disso, as disciplinas raramente contemplam conteúdos acadêmicos que efetivamente abordam tais objetivos, suscitando uma perspectiva dubitável sobre a sua eficácia.

Cabe observar que a oferta de disciplinas ministradas em língua inglesa não garante a internacionalização do currículo e tampouco assegura que os estudantes adquirirão as competências almejadas (Baltassar \& Mackenzie, 2016; Morosini \& Ustárroz, 2016). $\mathrm{Na}$ realidade, a supremacia desse idioma nos processos de internacionalização dificilmente pode ser associada a uma perspectiva de multiculturalismo. Complementarmente, a aprendizagem de idiomas estrangeiros é relevante para a apreciação de outras culturas, contudo, os estudantes precisam 
compreender a diversidade de valores, de pontos de vista e de quadros mentais existentes em torno do mundo (Baldassar \& Mckenzie, 2016).

Childress (2010), Leask, Beelen e Kaunda (2013), Whitsed e Green (2016) e Morosini e Ustárroz (2016) reforçam a necessidade de que o corpo docente esteja engajado no processo: é o coordenador acadêmico e as equipes de ensino que definem, controlam e gerenciam o currículo formal dos cursos e das disciplinas. Tal engajamento, entretanto, não é tão simples. Muitos deles parecem incertos sobre o significado da internacionalização dentro dos seus contextos disciplinares ou acham que esse fenômeno não lhes diz respeito. Nas palavras de Morosini e Ustárroz (2016, p 41), "postula-se como um dos grandes desafios, que cabe à docência, nesse contexto, manter o protagonismo de decisões reflexivas em vez de se constituir em mero executor de políticas globalizantes".

Lima e Maranhão (2011, p. 577), finalmente, argumentam que no lugar de suscitar a diversidade cultural, os processos correntes de internacionalização curricular promovem a defesa por uma forma particular de cultura, "que busca sua legitimação através da padronização dos curricula, dos programas de curso, dos idiomas e das experiências culturais". O comprometimento, nesse sentido, não ocorre com políticas curriculares dotadas de criticidade, mas com a lógica reprodutivista demandada pelo sistema de capital.

Nesse aspecto, cabe uma breve reflexão a respeito do tipo de conhecimento priorizado pelos processos de internacionalização curricular e, para tanto, resgatamos as palavras de Sousa Santos (1988, p. 46) em seu discurso sobre as ciências: "temos finalmente de perguntar pelo papel de todo o conhecimento científico acumulado no enriquecimento ou no empobrecimento prático das nossas vidas". Evidencia-se que a ordem hegemonicamente priorizada obedece ao paradigma eurocentrado da ciência moderna, que avança pela especialização, reconhece uma só forma de conhecimento verdadeiro e se preocupa antes com o "como funciona das coisas em detrimento de qual o agente ou qual o fim das coisas" (SOUSA SANTOS, 1988, p. 51). Trata-se de uma perspectiva que "nos ensina pouco sobre a nossa maneira de estar no mundo" (SOUSA SANTOS, 1988 , p. 69), e que, dessa forma, pode ter pouco tem a contribuir com as realidades sociais contextuais.

Observa-se, assim, a predominância de uma concepção funcionalista da ciência, a qual, segundo Andion (2012), busca produzir conhecimento científico útil e estimular 
uma visão exclusivamente objetiva do processo. Nesse sentido, limita as possibilidades de diálogo com percepções distintas e desconsidera a subjetividade, a historicidade e a contextualização próprias de cada meio, priorizando o tecnicismo acrítico e a manutenção do status quo.

Apesar desses obstáculos, a internacionalização curricular permanece como uma espécie de clichê para universidades e organizações governamentais e intergovernamentais envolvidas no contexto da educação superior internacional. A OCDE, por exemplo, cujo impacto nas políticas educacionais não pode ser desconsiderado, ressalta a necessidade de reformas curriculares mais condizentes com as demandas globais, voltadas à preparação dos estudantes para atuar socialmente e profissionalmente em um contexto internacional e multicultural (OCDE, 1996; Rizvi, 2007). Esse mesmo organismo tem desenvolvido um programa específico "para ajudar os países a aprimorar seu desempenho de ensino superior", visto que "muitos países têm dificuldades de acompanhar a evolução do panorama da educação superior e procuram aconselhamento da OCDE sobre as formas de melhorarem o desempenho de seus sistemas" (OCDE, 2016, p. 2, tradução nossa).

$\mathrm{Na}$ maioria dos casos, a idealização de internacionalização do currículo se embasa na análise fornecida pela OCDE. No entanto, além da falta de clareza sobre os meios para incorporar uma orientação internacional ao conteúdo curricular, ignora-se o fato de que muitos sistemas educacionais nacionais não estão bem preparados para avançar nesse caminho. Assim, observa-se uma tendência à generalização, que desconsidera as particularidades ou singularidades de cada sistema, denotando-se uma compreensão sofismável de facilidade do processo.

Como Lima e Maranhão (2011, p. 590) observam, apesar do discurso de valoração da multiculturalidade, "as políticas de internacionalização formuladas por governos e universidades tendem a reforçar determinado sistema de ensino já hegemônico [...]. Elas funcionam como ferramentas da indústria cultural, em favor da manutenção do status quo". Esse cenário, focado antes da padronização do que na diversidade, leva ao entendimento de que a internacionalização curricular requer análise, compreensão e aperfeiçoamento em sua concepção e prática, que incorporem considerações relativas às raízes epistêmicas dos contextos onde ocorre.

Morosini e Ustároz (2016, p. 39) argumentam que a possibilidade de construção de uma agenda transformativa para a internacionalização deve ter como base a 
diversidade cultural, "capaz de promover valores ligados ao entendimento, ao respeito e à tolerância. Para tanto, as comunidades acadêmicas precisam assumir uma posição mais ativa na formulação e concretização das políticas, das estratégias e das práticas de internacionalização.

Rizvi (2007), por sua vez, ciente de que o imaginário proposto para a internacionalização tem levado a reformas curriculares limitadas em escopo e despreparadas para envolver os estudantes na complexidade do mundo globalizado, propõe uma concepção mais crítica para esse processo, voltada ao desenvolvimento de virtudes epistêmicas que os permitam refletir, interpretar e se engajar criticamente aos processos contemporâneos da globalização. Tal concepção implica em um modo de pensar dialético, voltado à compreensão e à busca pela superação das tensões existentes entre as culturas.

Na percepção de Rivzi (2007), destacam-se entre tais virtudes a historicidade, a criticidade, a relacionalidade e a reflexividade. Esta última requer que os indivíduos estejam cientes dos seus próprios pressupostos culturais e políticos e de como eles estão sujeitos a transformações mediante seu engajamento a outras realidades. Com essa consciência, eles se tornam mais bem preparados para desafiar os conceitos tomados como certos, frequentemente encontrados nos discursos oficiais e populares. Assim, uma abordagem crítica para a internacionalização do currículo envolve tanto uma visão da interconectividade e interdependência quanto uma atitude ética em relação às trocas interculturais. Como Morosini e Ustárroz (2016, p. 39) argumentam, "um ensino de qualidade, no contexto da internacionalização, é um ensino que assume essa responsabilidade social"'.

Diante dessa conjuntura, destaca-se a necessidade de que as universidades dos países do Sul determinadas a investir na internacionalização de seus currículos estejam cientes de que a importação acrítica de modelos prontos pode comprometer os resultados almejados com esse processo. Se tal modelo não estiver relacionado com as raízes do contexto onde ocorre, é provável que apenas reproduza e reforce uma produção de conhecimento com pouco valor para a sua realidade, limitando e dissipando o potencial da formação universitária. Em outras palavras, é provável que favoreça a articulação de histórias culturais diversas e heterogêneas em torno de uma única ordem global. Assim, parece relevante que caminhos pouco explorados, pautados em referenciais interpretativos e críticos, sejam pensados para esse campo. 


\section{Internacionalizaçao do currículo e os conceitos de redução sociológica e de epistemologias do sul}

O primeiro conceito que apresentamos no intuito de fomentar uma reflexão sobre as condicionalidades dos países do Sul no domínio da internacionalização curricular é a redução sociológica. Trata-se de uma intuição do sociólogo brasileiro Guerreiro Ramos, concebida em uma perspectiva fenomenológica e proposta sistematicamente em 1958 como atitude metódica para a constituição de uma sociologia autenticamente nacional (Guerreiro Ramos, 1996; Azevêdo, 2006). Recentemente, o pensamento de Guerreiro Ramos tem sido situado no domínio da teoria pós-colonial (Lynch, 2015; Bringel, Lynch \& Maio, 2015), "uma teoria que, no caso brasileiro, deveria substituir a sociologia cêntrica na tarefa de orientar pesquisas empíricas, tendo em vista sua inadequação nas circunstâncias periféricas" (Lynch, 2015, p. 27).

Fundamentada na constante preocupação do autor com a produção de conhecimento comprometido e engajado, dotado de valor pragmático, em contraposição a um saber alienado e ideológico (Azevêdo, 2006), que trata os fatos sociais como estáveis e isolados no tempo e no espaço (Lynch, 2015), a redução sociológica é perspectivista; refere-se a um procedimento crítico-assimilativo da experiência estrangeira, que se contrapõe à transposição acrítica das determinações exteriores (Guerreiro Ramos, 1996).

Com base nesse conceito, entende-se que no lugar da importação passiva e da reprodução literal de modelos curriculares estrangeiros, o engajamento dos países periféricos e semiperiféricos em processos ativos de internacionalização implica no estabelecimento de uma assimilação crítica, autoconsciente dos seus fatores situacionais e orientada segundo o contexto histórico-social em que eles se integram. Para Guerreiro Ramos (1996, p. 48), "a consciência crítica surge quando um ser humano ou um grupo social reflete sobre tais determinantes e se conduz diante deles como sujeito. Distinguese da consciência ingênua, que é puro objeto de determinações exteriores". Trata-se, portanto, de uma atitude altamente elaborada, passível de alcance principalmente através de um modo de ver histórico, que "só ocorre e se faz necessária nos países que estão empenhados numa tarefa substitutiva" (Guerreiro Ramos, 1996, p. 88). 
No contexto dos estudos sobre internacionalização curricular, associamos o conceito de redução sociológica à demanda por uma visão mais realista do contexto mundial, que apreenda o "caráter dinâmico e situado da realidade" (Lynch, 2015, p. 30) e permita incidir luz sobre as limitações da "ilusão etnocêntrica" (Guerreiro Ramos, 1996, p. 159) na construção de currículos universitários nos países do Sul. Essa perspectiva, que implica na "inteligibilidade de uma realidade local, culturalmente específica, reflexiva, embasada em experiência societária original" (Bringel, Lynch \& Maio, 2015, p. 11), se apresenta como caminho para a construção de um saber engajado e comprometido, assim como contribui para que a importação automática de ideias e objetos culturais acabados e descontextualizados, que em nada se ajustam à realidade dessas nações, não as satisfaçam.

Trata-se, portanto, de que os países do Sul busquem produzir ideias e objetos alternativos, condizentes com o seu contexto histórico-social, em uma perspectiva voltada à consolidação de um destino próprio, pautado em uma individualidade subjetiva, que permita a essas nações enxergar-se como próprio centro de referências (Guerreiro Ramos, 1996). Como Rivzi (2007) pondera, a internacionalização do currículo requer análise, compreensão e aperfeiçoamento em sua concepção e prática, que incorporem considerações relativas às raízes epistêmicas dos contextos em que ocorrem. Morosini e Ustarróz (2016, p. 39) contribuem com essa perspectiva analítica, ao argumentarem que

"em vez de acriticamente responder às exigências externas, envidando esforços para além de suas possibilidades no intuito de atender aos padrões preestabelecidos, é preciso refletir sobre a cidadania global, tendo como base as especificidades culturais e as necessidades socioeconômicas do contexto educacional em que se está inserido, buscando afirmar que os processos de internacionalização da educação superior também respondem a uma responsabilidade social".

Da mesma forma que a realidade social é perspectivista e não se constitui como "conjunto desconexo dos fatos, mas é sistemática, dotada de sentido, visto que sua matéria é a vida humana" (Guerreiro Ramos, 1996, p. 73), também a internacionalização curricular o é. Quando transferidos para outro prisma, os objetos deixam de ser exatamente o que eram; seu sentido jamais se desliga de um determinado contexto. Dessa forma, a incorporação de modelos estrangeiros só faze sentido se 
assume caráter subsidiário (Guerreiro Ramos, 1996); se considera o caráter dinâmico e situado da realidade (Lynch, 2015).

Ainda na perspectiva da redução sociológica, a razão dos problemas de uma sociedade particular sempre se dá pela fase em que essa sociedade se encontra (Azevêdo, 2006). Considerando-se que, de maneira geral, os sistemas educacionais dos países periféricos e semiperiféricos ainda não ultrapassaram as limitações históricas de insuficiente cobertura e reduzida qualidade do ensino e da pesquisa (Lima \& Contel, 2011), depreende-se que a importação literal de modelos de internacionalização prontos, desajustados às necessidades concretas de desenvolvimento, dificilmente contribuirão para o alcance de níveis significativos de internacionalização curricular e, em perspectiva mais ampla, para a diminuição do processo histórico de exclusão desses países.

Assim, somente para uma sociedade conscientemente seletiva no que se refere à importação estrangeira, consciente dos seus condicionamentos interiores e exteriores, um fenômeno como a internacionalização do currículo poderá ser verdadeiramente funcional e significativo às suas demandas. Para tanto, deverá associar-se a uma perspectiva de real aprimoramento da qualidade, da pertinência e da relevância do ensino superior. Como Guerreiro Ramos (1996, p. 86) argumenta, "não tem sentido reunir em mostruário objetos de culturas diferentes, pois cada um deles só pode ser compreendido no seu contexto".

Um segundo conceito que embasa nossa discussão sobre internacionalização curricular no contexto dos países periféricos e semiperiféricos é o de epistemologias do Sul, desenvolvido em uma perspectiva pós-colonial pelo sociólogo português Boaventura de Sousa Santos como crítica à hierarquização de saberes proveniente da natureza hierárquica das relações Norte-Sul (Meneses, 2008; Sousa Santos \& Meneses, 2010). Trata-se da constatação de que os sistemas econômicos e políticos, assim como as culturas e os saberes de raiz eurocêntrica se sobrepõem às perspectivas originalmente oriundas dos espaços colonizados, levando-as a uma condição de subalternidade e de esquecimento (Meneses, 2008).

Segundo Sousa Santos e Meneses (2010), a epistemologia dominante nos dois últimos séculos excluiu de seu escopo o contexto cultural e político da produção e reprodução do conhecimento, pautando-se exclusivamente em uma pretensão universalista, que desconsidera as práticas sociais de conhecimento que contrariam os 
interesses a que ela serve. Sob essa ótica, as diferenças são suprimidas e cedem espaço a uma cultura dominante, que reduz ao mínimo as diversidades epistemológicas, culturais e políticas do mundo, levando à perda de uma autorreferência genuína para esses povos. Impera, portanto, um pensamento abissal, no qual uma divisão metafórica e invisível se estabelece e separa as sociedades metropolitanas dos territórios coloniais, fazendo com que estes desapareçam enquanto realidade (Sousa Santos, 2010). Como Meneses (2008, p. 6) argumenta, "o que não está conforme o definido pela racionalidade moderna volatiza-se e desaparece”.

A ideia se assenta, portanto, no pressuposto de que as experiências sociais somente se tornam intencionais e inteligíveis por meio do conhecimento válido, que é "sempre contextual, tanto em termos de diferença cultural como em termos de diferença política" (Sousa Santos \& Meneses, 2010, p. 16). Sousa Santos e Meneses (2010) advogam que o reconhecimento da pluralidade epistemológica do mundo, designada de epistemologias do Sul, constitui-se como fonte de enriquecimento significativo das capacidades humanas no que se refere à inteligibilidade e intencionalidade das experiências sociais, em uma perspectiva contrária à supressão das contextualidades. Em suas palavras, "as epistemologias do Sul são o conjunto de intervenções epistemológicas que denunciam essa supressão, valorizam os saberes que resistiram com êxito e investigam as condições de um diálogo horizontal entre conhecimentos" (Sousa Santos \& Meneses, 2010, p. 19).

No que se refere à internacionalização curricular nos países do Sul, esse conceito vem reforçar a necessidade de que as análises e avaliações nesse campo se tornem mais complexas e considerem as especificidades contextuais e os saberes alternativos que emergem "deste lado da linha" (Sousa Santos \& Meneses, 2010, p. 33). Como Sousa Santos (1995, p. 508 apud Sousa Santos \& Meneses, 2010, p. 15) aponta, "uma epistemologia do Sul assenta em três orientações: aprender que existe o Sul; aprender a ir para o Sul; aprender a partir do Sul e com o Sul”. É fundamental, portanto, que as diferentes culturas tenham imagens concretas sobre si próprias e sobre as outras (Meneses, 2008), o que é possível por meio do desenvolvimento de "virtudes epistêmicas" que os permitam refletir, interpretar e se engajar criticamente aos processos contemporâneos da globalização.

Trata-se de um exercício profundo de autoreflexividade por parte dos formuladores de políticas educacionais e de planos institucionais de internacionalização 
desses países, assim como do corpo docente engajado no processo, que considere as alternativas epistêmicas locais disponíveis, no sentido de contribuir para que a biodiversidade dos conhecimentos existentes se transforme em caminho para uma internacionalização útil e significativa a essas sociedades. Isso porque a concretização de um currículo que tenha como um dos objetivos de aprendizagem o desenvolvimento de competências voltadas a uma interação positiva e efetiva entre membros de diferentes culturas "depende da articulação dos diferentes níveis - políticas governamentais, estratégias institucionais e práticas docentes - para que sejam produzidas as condições necessárias para um ensino assim orientado" (Morosini \& Ustárroz, 2016, p. 41).

À luz das epistemologias do Sul, os processos de internacionalização curricular nos países periféricos e semiperiféricos implicariam em uma revisão crítica dos conceitos hegemonicamente definidos pela racionalidade moderna em termos históricos, ontológicos e epistêmicos ${ }^{5}$. A interculturalidade, portanto, se apresentaria como proposta metodológica, o que, em termos práticos, poderia se concretizar através de iniciativas de cooperação Sul-Sul e de outras práticas colaborativas que implicassem em uma relação de benefício mútuos entre os parceiros, com a valorização do compartilhamento de experiências.

Em resumo, à luz dos conceitos de redução sociológica e de epistemologias do Sul, a internacionalização curricular no contexto universitário do Sul-Global procuraria contemplar diferentes lógicas e formas de pensar, com criticidade e assimilação crítica em relação às determinações exteriores, no lugar de incorporar uma forma particular de cultura (eurocentrada), própria de um sistema produtivo que tende a reduzir a Universidade às suas demandas.

\section{Conclusão}

O objetivo deste ensaio foi apresentar uma reflexão teórica sobre a internacionalização curricular no contexto nos países do Sul, a partir de dois conceitos

\footnotetext{
${ }^{5}$ A exigência histórica se refere à "necessidade de repensar todos os passados e perspectivas futuras à luz de outras perspectivas, que não as do Norte global"; a exigência ontológica "passa pela renegociação das definições do ser e dos seus sentidos" e a exigência epistêmica "contesta a compreensão exclusiva e imperial do conhecimento, desafiando o privilégio epistêmico do Norte global" (Meneses, 2008, p. 6).
} 
sociológicos relacionados à teoria pós-colonial: redução sociológica, de Alberto Guerreiro Ramos, e epistemologias do Sul, de Boaventura de Sousa Santos.

Buscou-se estabelecer um diálogo que tivesse como referencial uma perspectiva crítica acerca dos processos de internacionalização no campo da educação superior e, mais especificamente, da internacionalização curricular, advogando a necessidade de que as reformas estabelecidas nesse domínio estabeleçam uma assimilação crítica em relação às determinações exteriores, que muitas vezes não se ajustam às suas realidades, e que incorporem considerações relativas às raízes epistêmicas dos contextos em que ocorrem. Como Lima e Contel (2011) constatam, na ausência de políticas públicas e programas claros e ajustados às realidades internas, as instituições universitárias dos países periféricos e semiperiféricos acabam por constituir-se como alvo fácil dos interesses externos que visam tão somente ao ativo econômico.

Enfatizamos que a reflexão proposta a partir dos conceitos de redução sociológica e de epistemologias do Sul não objetivou suscitar "isolacionismo ou exaltação romântica do local, regional ou nacional" (Guerreiro Ramos, 1996, p. 73) e tampouco propor "relativismo epistemológico ou cultural" (Sousa Santos \& Meneses, 2010), mas sugerir um procedimento crítico-assimilativo da experiência estrangeira, pautado em conhecimento prudente, válido, contextual, que enfatize a "descolonização do saber" (Meneses, 2008, p. 10) e torne a internacionalização curricular funcional e significativa nas distintas conjunturas onde ocorre, visto que "o sentido de um objeto jamais se dá desligado de um contexto determinado" (Guerreiro Ramos, 1996, p. 72).

Para finalizar a reflexão, registramos nosso posicionamento acerca da necessidade de que, no lugar de promoverem a padronização das culturas e das consciências (Lima \& Maranhão, 2011), os processos de internacionalização curricular do Sul contemplem as diferenças culturais em sua plenitude e, ao mesmo tempo, contribuam para a formação de cidadãos dotados de virtudes epistêmicas como a interpretatividade e a reflexividade. Em outras palavras, cidadãos conscientes de sua condição e "sensíveis aos assuntos relevantes de sua sociedade" (Guerreiro Ramos, 1996, p. 79), engajados com o destino de seu povo, capazes de desafiar conceitos aparentemente justificados, de refletir e de intervir criticamente em um mundo revestido de complexidade, que nos redesenha continuamente. Como Guerreiro Ramos (1996, p. 48) argumenta, "sem consciência crítica, o ser humano ou o grupo social é coisa, é matéria bruta do acontecer". 
Sobretudo nos países do Sul é pertinente que os sujeitos adquiram uma individualidade subjetiva, por meio de uma tarefa interpretativa, e enxerguem a si próprios como centro de referências, capazes de determinar o seu próprio caminho, como um eu teórico, reflexivo e não ingênuo (Guerreiro Ramos, 1996). Sob essa perspectiva, parece oportuno que os processos de internacionalização curricular prontos e descontextualizados cedam lugar a programas com uma visão ampla e universal para a compreensão da realidade, buscando alternativas como a cooperação e a integração, sem supor, contudo, a perda das identidades e tampouco a diluição da missão e da função social das instituições educacionais ou as necessidades internas de desenvolvimento dessas nações.

\section{Referências}

Altbach, P. \& De Wit, H. (2015). Internationalization and global tensions: lessons from history. Journal of studies in international education, 19(1), 4-10.

Andion, C. (2012). Por uma nova interpretação das mudanças de paradigma na administração pública. Cadernos EBAPE.BR, 10(1), Rio de Janeiro, mar.

Azevêdo, A. (2006). A redução sociológica em perspectiva histórica. XXX Encontro Anual da Anpad. Salvador.

Baldassar, L. \& Mckenzie, L. (2016). Beyond "just being there": teaching internationalization at home in two qualitative methods units. Teaching Sociology, 4(2).

Bringel, B; Lynch, C. \& Maio, M. (2015). Sociologia periférica e questão racial: revisitando Guerreiro Ramos. Caderno CRH, Salvador, 28(73), 9-12, Jan./Abr.

Childress, L. (2010). The twenty-first century university: developing faculty engagement in internationalisation. New York: Peter Lang. 
Deardorff, D. \& Jones, E. (2012). Intercultural competence: an emerging focus. In:

Deardoff, D; De Wit, H; Heyl, J. \& Adams, T (eds). The SAGE Handbook of Internationalization, 283-304. California: SAGE Publications.

Egron-Polak, E. \& Hudson, R. (2014). Internationalization of higher education: growing expectations, fundamental values. IAU $4^{\text {th }}$ Global Survey. IAU.

Ewert, S. (2012). Higher Education Cooperation and Networks in the Baltic Sea Region: A Basis for Regionalization and Region Building? Journal of Baltic Studies, 43(1), 95-116, mar.

Gacel-Ávila, J. \& Ávila, R. (2008). Universidades latinoamericanas frente al reto de la internacionalización. Casa del Tiempo, jul. 2008.

Gomes, A. M.; Robertson, S. L. \& Dale, R. (2012). The social condition of higher education: Globalisation and (beyond) regionalisation in Latin America. Globalisation, Societies and Education, 10(2), 221-245.

Guerreiro Ramos, A. (1996). A redução sociológica. 3 ed. Rio de Janeiro: Editora UFRJ.

Knight, J. (2004). Internationalization remodeled: definition, approaches, and rationales. Journal of Studies in International Education, 1(1), 5-31. Spring.

Knight, J. (2008). The Internationalization of Higher Education: complexities and realities. In: Terrefa, D. \& Knight, J. Higher education in Africa: the international dimension. Massachussetts, USA: Boston College.

Knight, J. (2012). Student mobility and internationalization: trends and tribulations. Research in Comparative \& International Education, 7(1).

Knight, J. (2015). International universities: misunderstandings and emerging models? Journal of Studies in International Education, 1-15. 
Knight, J. \& De Wit, H. (1995). Strategies for internationalisation of higher education: historical and conceptual perspectives. In: DE WIT, Hans (ed.). Strategies for the internationalisation of higher education. Amsterdam: EAIE.

Laus, S. (2012). A internacionalização da educação superior: um estudo de caso da Universidade Federal de Santa Catarina. Tese (Doutorado em Administração). Salvador: Universidade Federal da Bahia.

Leask, B. (2015). Internationalizing the curriculum. New York: Routledge.

Leask, B; Beelen, J. \& Kaunda, L. (2013). Internationalisation of the curriculum: international approaches and perspectives. In: De Wit, H.; Hunter, F.; Johnson, L. \& Van Liempd, H. (eds). Possible futures: the next 25 years of the internationalisation of Higher Education. Amsterdam: EAIE.

Leite, I. (2012). Cooperação Sul-Sul: conceito, história e marcos interpretativos. Observador on-line, 7(3), mar.

Lima, M. \& Contel, F. (2011). Internacionalização da educação superior: nações ativas, nações passivas e a geopolítica do conhecimento. São Paulo: Alameda.

Lima, M. \& Maranhão, C. (2011). Políticas curriculares da internacionalização do ensino superior: multiculturalismo ou semiformação? Ensaio, 19(72), 575-598, Jul./Set.

Lynch, C. (2015). Teoria pós-colonial e pensamento brasileiro na obra de Guerreiro Ramos: o pensamento sociológico. Caderno CRH, Salvador, 28(73), 27-45, Jan./Abr.

Marx, K. \& Engels, F. (2003). O manifesto comunista. São Paulo: Martin Claret. Meneses, M. (2008). Epistemologias do Sul. Revista Crítica de Ciências Sociais, 80. 
Miura, I. (2009). O processo de internacionalização da Universidade de São Paulo: um estudo em três áreas do conhecimento. XXXIII Encontro da ANPAD. São Paulo: Anpad.

Morosini, M. (2006). Estado do conhecimento sobre internacionalização da educação superior: conceitos e práticas. Educar, Curitiba, 28, 107-124.

Morosini, M. \& Ustárroz, E. (2016). Impactos da internacionalização da educação superior na docência universitária: construindo a cidadania global por meio do currículo globalizado e das competências interculturais. Em Aberto, 29(97), 35-46.

OCDE. (1996). Internationalizing the curriculum in higher education. Paris: OCDE.

OCDE. (2016). Enhancing higher education system performance: how to become involved in the OECD's new work on higher education. OCDE.

Rizvi, F. (2007). Internationalization of curriculum: a critical perspective. In: Hayden, M; Levy, J; Thompson, J. (eds.). The Sage handbook of international education. London: Sage.

Santos, M. (2013). Por uma outra globalização: do pensamento único à consciência universal. 23 ed. Rio de Janeiro: Record.

Santos, M.; Souza, M. A. \& Silveira, M. L. (2002). Território: globalização e fragmentação. 5. ed. São Paulo: Editora Hucitec.

Sebastián, J. (2004). Cooperación e internacionalización de las universidades. 1 ed. Buenos Aires: Biblos.

Seeber, M. et. al. (2016). Why do higher education institutions internationalize? An investigation of the multilevel determinants of internationalization rationales. Higher Education, 72(5), 685-702. 
Sousa Santos, B. (1988). Um discurso sobre as ciências. Coimbra: Edições Afrontamento.

Sousa Santos, B. (2011). A globalização e as ciências sociais. São Paulo: Cortez.

Sousa Santos, B. (2010). Para além do pensamento abissal: das linhas globais a uma ecologia de saberes. In: Santos, B. Meneses, M. Epistemologias do Sul. São Paulo: Cortez Editora.

Sousa Santos, B. \& Meneses, M. (2010). Epistemologias do Sul. São Paulo: Cortez Editora.

Unesco. (2003). Educação Superior: reforma, mudança e internacionalização. Brasília: Unesco Brasil.

Unesco. (2015). Educação para a cidadania global: preparando alunos para os desafios do século XXI. Brasília: Unesco Brasil

Unesco. (2016). Educação para a cidadania global: tópicos e objetivos de aprendizagem. Brasília: Unesco Brasil.

Wallerstein, I. (2004). Impensar a ciência social: os limites dos paradigmas do século XIX. São Paulo: Ideias \& Letras.

Whitsed, C. \& Green, W. (2016). Lessons from Star Trek: engaging academic staff in the internationalisation of the curriculum. International Journal for Academic Development, 1-13, Abr. 